\section{THE GREAT ALPINE TUNNELS.}

THE subject for this evening's discourse is that of the three great tunnels through the Alps-viz. the Mont Cenis, the St. Gothard, and that which is now in course of construction, the Simplon.

But before dealing with the details of these particular works, it will be desirable to consider what tunnelling is, and also some of the more remarkable instances of it in bygone days.

One great drawback in connection with the subjectso far as a discourse is concerned-is its unsuitability for the photographic art. Unlike a battleship, or a splendid bridge, or a grand block of buildings which can be made into fine views and pictures, the work of the mole is hardly adapted to the sensitive plate. I therefore propose to make use of the "language of the pencil," and to make a few rough sketches on the blackboard : by these means I trust I may be able to explain some of the difficulties which have to be encountered, and aiso show how a tunnel is constructed. The child's definition of drawing, "first you think, and then you draw a line round your think," will come to our aid.

The art of tunnelling dates back to very remote ages, and there are records of such works which were constructed 500 to 600 years before the Christian era.

An interesting account is given by one of your most distinguished members, in an article in the "Encyclopæedia Britannica," of the tunnel under the river Euphrates at Babylon. This city, similar in some respects to London, lay half on one side and half on the other side of the river. High walls, pene.

Fig. I.

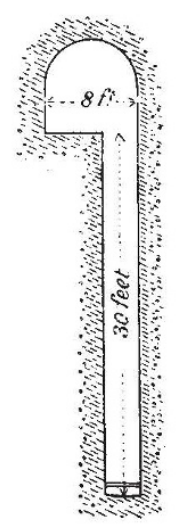

\section{CROSS SECTION of the}

AQUEDUCT of EUPALINOS.

In the Island of SAMOS

trated by occasional gates, surrounded the city, and lined each of the banks of the river. These gates (of which a pair of the great hinges can be seen in the British Museum) were closed at night and during war ; and a tunnel was constructed below the bed of the river by means of what is technically known as the "cut-and-cover" system. In those days the Greathead shield was unknown, and consequently the river had to be diverted, so that the excavation could be made in the dry bed and cut open to daylight, the arch being built, the ground restored, and the river allowed to resume its former course. The tunnel is said to have been 15 feet in width, and 12 feet in height, built of brick.

Herodotus gives an account of the diversion of the river into a great excavation or artificial lake forty miles square, and states that the besieging enemy, so soon as the water was drawn off, entered into the city by the river bed. It is believed that this same excavation was made use of for the construction of the tunnel. It is, however, desirable to state that doubts have been thrown on the subject, and it is possible that it may have to be relegated to mythology.

The next instance of a tunnel is that referred to by Herodotus in the Island of Samos ("Herodotus," iii. p. 60) (see Fig. I), and it is satisfactory to know that although very considerable doubts were expressed as to the accuracy of his statements, recent investigations prove that he was exactly correct. The description given by him, when expressed in English words and figures, is as 1 A discourse delivered at the Royal Institution on Friday, May 25, by Francis Fox, Mem.Inst.C. E. follows : "They have a mountain which is 910 feet in height ; entirely through this they have made a passage, the length of which is 1416 yards. It is, moreover, 8 feet high, and as many wide. By the side of this there is also an artificial canal, which in like manner goes quite through the mountain; and though only 3 feet in breadth, is 30 feet deep. This, by the means of pipes, conveys to the city the waters of a copious spring."

The commentators on this passage say that Herodotus must have made a mistake, but the Rev. H. F. Tozer, in his book " The Islands of the Egean," p. I67, gives the results of a personal visit.

He says the tunnel is 7 to 8 feet in width; that two-thirds of its width are occupied by a footpath, the other third being a watercourse, 30 feet deep at one end. He and other writers consider that insufficient allowance was made for the fall of the water, and that the water channel had to be deepened. To describe it in more modern language, the resident engineer evidently made a mistake in his levels, necessitating a much deeper excavation than was at first anticipated.

Another, and if possible a more interesting, instance of tunnelling is that described in the Proceedings of the Palertine Exploration Society, in connection with the Pool of Siloam, made by Hezekiah, B.c. 7 I0, 2 Kings xx. 20 ("Palestine Exploration," I882, p. I78). See Fig. 2.

About 7 IO B.C. a tunnel was driven from the spring to the well-by actual tunnelling-the work being commenced at the two ends, and by shafts, and the workmen met in the middle. The tunnel was only 2 feet in width and 3 feet in height, except at the probable point of meeting, where the height is 4 feet 6 inches. The length is 1708 feet, and there is a fall of 1 foot in this distance. About the middle of its course there are apparently two false cuts, as if a wrong direction had been

Fig. 2 .

\section{Plan of Tunnel from Spring to Pool of Siloam.}

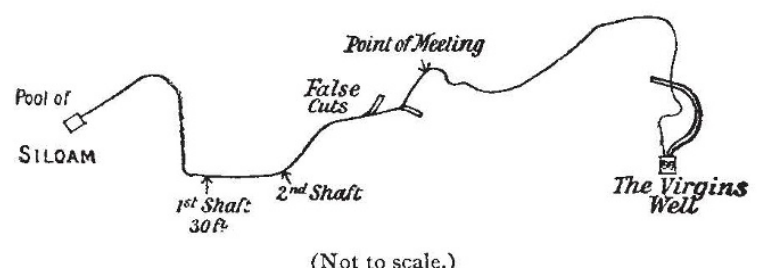

taken : but possibly these were intentional, and provided passing places for the workmen and material.

On the soffit of the tunnel is carved an inscription, of which the following is a translation :-

"Behold the excavation. Now this had been the history of the excavation. While the workmen were still lifting up the pick, each towards his neighbour, and while 3 cubits ( 4 feet 6 inches) still remained to cut through, each heard the voice of the other, who called to his neighbour, since there was an excess of rock on the right hand and on the left. And on the day of the excavation the workmen struck each to meet his neighbour pick against pick, and there flowed the waters from the spring to the pool for a thousand two hundred cubits (I820 feet), and a hundred cubits ( $15 \mathrm{I}$ feet) was the height of the rock over the head of the workmen."

A Roman engineer gives an account of a tunnel which was being driven under his directions for an aqueduct. And as he was only able to visit the work occasionally, he describes how on one of his visits he found the two headings had missed each other, and he says that had his visit been deferred much longer there would have been two tunnels.

The accurate meeting of the headings or driftways of a tunnel can only be attained by the exercise of great care, both as regards direction as well as level.

We need not go very far to find instances of such an error as inaccurate meeting, but there is one well-known case on an im. portant main line in the Midland Counties where the engineers failed to meet, and to this day reverse curves exist in the tunnel to overcome the difficulty.

To attain this accurate meeting fine wires are hung down the 
shafts of a tunnel, with heavy plumb-bobs suspended from them in buckets of water, or of tar, to bring their oscillations to rest ; the accurate direction being given by means of a theodolite or transit instrument on the surface.

The wires are capable of side movement by means of a delicate instrument, and are gradually brought exactly into the same vertical plane : hence, if they are correct at "bank," or surface, they must also be correct below ground. The engineers below have to drive the galleries or headings so that only one wire is visible from their instrument: so long as one wire exactly eclipses the other wire, the gallery is being driven in the right direction.

As regards accuracy in levels, this is done by ordinary level. ling; but it wili be seen at once how much depends on care being devoted to both these operations.

$$
\text { Fig. } 3 .
$$

\section{PLAN.}

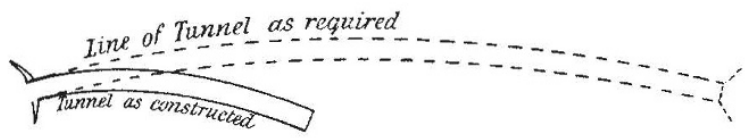

Assume two shafts, 1000 yards apart, between which a gallery has to be driven; and, allowing a distance of 10 feet between the wires, which are ${ }_{4}^{1}$ th inch in diameter, an error of the diameter of the wire at the shaft will cause a mistake of nearly 4 inches at the point of meeting, or of $7 \frac{1}{2}$ inches if a similar error occurs at the other shaft in the opposite direction. The trickling of water down the wires increases their diameter so appreciably, and therefore conduces to further inaccuracy, that it is found necessary to fix a small shield or umbrella on the wire to deflect the water.

Some years ago, a tunnel which had been commenced, but not finished, had to be completed. The first thing to be done by the engineers was to make an accurate survey of the then condition of the work - this rough sketch (see Fig. 3 ) indicates what was discovered. The explanation given by the former "ganger" was, that he found the rock too hard, and he thought that by bearing round somewhat to the right, he might get into more easily excavated material !

When the wires are hung down the shaft it is sometimes almost impossible to prove that they are not touching, and consequently being deflected from the true vertical line by some rope or pipe, staging or timber in the shaft. To overcome this, an electrical current was passed down the wire-a galvanometer being in circuit. If the wire proved absolutely silent, and no deflection was obtained in the galvano. meter, the conclusion could be safely drawr. that the wire was hanging freely and truly.

In driving the necessary adit or heading for drainage purposes beneath a sub-aqueous tunnel, a rising gradient from the shaft bottom of 1 in 500 is allowed, to enable the water at the "face" to flow away from the workmen to the pumps in the "sump" or shaft bo: tom (see Fig. 4).

When the heading is driven sufficiently forward to justify the commencement of the main tunnel, a fresh difficulty presents itself. This main tunnel has to be driven down hill, and consequently the water collects at the working face $\mathrm{A}$ : the bottom cannot therefore be removed until a bore-hole is put down from A to $a$. When this is done the remaining excavation can be taken out, and a further length of tunnel driven to B. A borehole is now sunk from $\mathrm{B}$ to $b$, whilst that from $\mathrm{A}$ to $a$ can be plugged up: and thus the tunnel is gradually advanced.

By the adoption of the Greathead shield much of this difficulty can be avoided; but one sub-aqueous tunnel through water-bearing strata, at considerable depth, is sufficient for a lifetime.

As an illustration of the danger to which men are exposed in such work, it is stated, with much regret, that in a certain tunnel, notwithstanding every precaution being taken, all the men engaged in driving the drainage heading by means of a tunnelling machine have died; and in the case of the first Vyrnwy tunnel crossing of the River Mersey-driving by Greathead shield under pressure-the mortality was great.

Having explained in very general terms some of the difficulties of tunnel construction, we will proceed to the case of the great tunnels through the Alps, and for the purpose of rendering the subject more easily intelligible, the following particulars may be given :-

\begin{tabular}{|c|c|c|c|c|}
\hline & St. Gothard & Mont Cenis & Arlberg & Simplon \\
\hline $\begin{array}{c}\text { Length of tunnel in } \\
\text { miles }\end{array}$ & $9 \cdot 3$ & $7 \cdot 98$ & $6 \cdot 36$ & I $2 \cdot 26$ \\
\hline North or east portal & & & & \\
\hline $\begin{array}{l}\text { above sea-level, feet } \\
\text { South or west portal }\end{array}$ & 3639 & 3766 & 4296 & 2254 \\
\hline above sea-level, teet & 3757 & 4164 & 3998 & 2080 \\
\hline $\begin{array}{l}\text { Highest level } \ldots \ldots \\
\text { Maximum grade } \ldots\end{array}$ & 3788 & 4248 & 4300 & 2314 \\
\hline $\begin{array}{r}\text { tunncl per rooo } \ldots \\
\text { Maximum height of }\end{array}$ & 582 & 30 & I 5 & 7 \\
\hline $\begin{array}{l}\text { meunt, feet... } \ldots \ldots \ldots \\
\text { Possible } \ldots . . .\end{array}$ & 5598 & 5428 & 2362 & 7005 \\
\hline $\begin{array}{l}\text { temperature of rock, } \\
\text { deg. Fahr. } \quad \ldots \quad \ldots\end{array}$ & $85^{\circ}$ & $85^{\circ}$ & $65^{\circ}$ & $104^{\circ}$ \\
\hline
\end{tabular}

\section{Mont Cenis Tunnei.}

The Mont Cenis, or as it is more accurately called, the Frejus Tunnel, is nearly eight miles in length. It is for a double line of way-width being 26 feet, and height above rails 20 feet 6 inches.

In consequence of the gradients in the Mont Cenis ascending

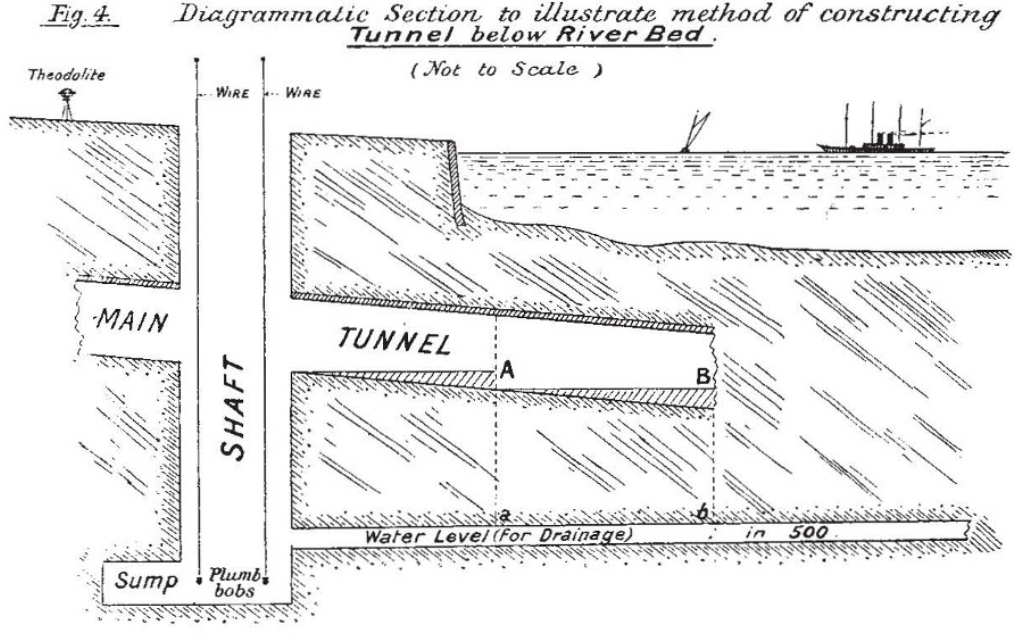

from both ends, the smoke cannot get away, and it remains in a dull, heavy cloud in the tunnel. It is worse during cold and rainy weather, and particularly during, the winter, when the air is sometimes so deficient in oxygen that the plate-layers cannot work.

Trains coming from France with an ascending gradient of $I$ in 40 against them for a length of 7 kilometres, when followed by a current of air in the same direction, produce a disastrous state of things. In this, as in all other steep tunnels, engines having a heavy load behind them go through with their regulators full open, ejecting great volumes of smoke and steam which travel concurrently with the train, and the inconvenience and discomfort produced are very great.

At each kilometre in the tunnel, a refuge or "grande chambre" is provided for the men, and this is supplied with compressed NO. 1603 , VOL. 62 ] 
air, fresh water, a telephone in each direction out, a medicine chest, barometer and thermometer.

The cost of the tunnel was about 3,000,000l., or 220l. per yard, and occupied ten years in construction.

The temperature in the middle of the tunnel remains nearly constant, summer and winter, and is about $19^{\circ}$ to $20^{\circ} \mathrm{C}=66^{\circ}$ to $68^{\circ} \mathrm{Fahr}$.

The altitude of the tunnel is 4248 feet above sea-level, and the height of the mountain above the tunnel is 5428 feet : the temperature of the rock is greatly influenced by this latter fact.

The question of the temperature of the rocks passed through in the construction of a tunnel is one of great interest, as it depends upon several conditions: (I) the character of the rock;

Fig. 5.

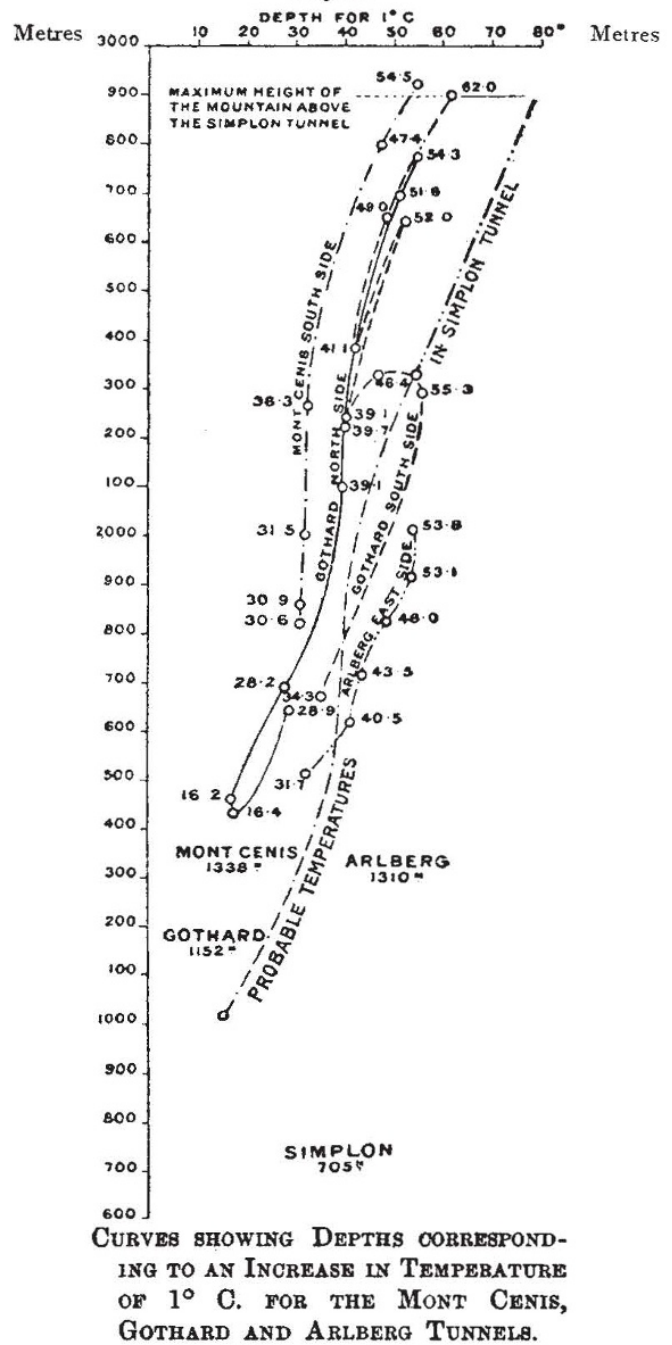

(With curve of probable temperature for the Simplon Tunnel.)

(2) the inclination of the beds-those which attain a vertical or nearly vertical position being less able to confine the heat than those which are more or less horizontal ; (3) the height of the mountain above the tunnel, or in other words, the thickness of the blanket.

A diagram is shown (Fig. 5), giving the temperature actually encountered in the St. Gothard and Arlberg Tunnels, and from these, aided by the carefully prepared geological section along the centre line of the Simplon Tunnel, an approximate line is given of the temperatures which are expected.

The possibility of cooling the rocks and the air of the tunnel will be dealt with later on, but there is in addition a permanent lowering of the temperature after the tunnel is complete, particulars of which will be given under the description of the St. Gothard.

For each 144 feet of superincumbent rock or earth the increase is found to be $I^{\circ} \mathrm{Fahr}$.

\section{The St. Gothard Tunnel.}

This, which is at present the longest railway tunnel in. the world, is 9.3 miles in length, and constitutes the summit of the "Gothard bahn," that is, the railway which runs from Lucerne to Chiasso near the Italian frontier.

The altitude of the tunnel at its north portal is 3639 feet, and at its south portal 3757 feet above the sea. A gallery of direction was driven throughout, and the gradient of the rails is only such as to provide for efficient drainage, viz. 5.82 per thousand, or about $\mathrm{I}$ in 172 .

The following table may be of interest, giving the result of investigations as to the cooling of the rocks.

TEMPerature of THE Rock in The ST. Gothard TUNNEL.

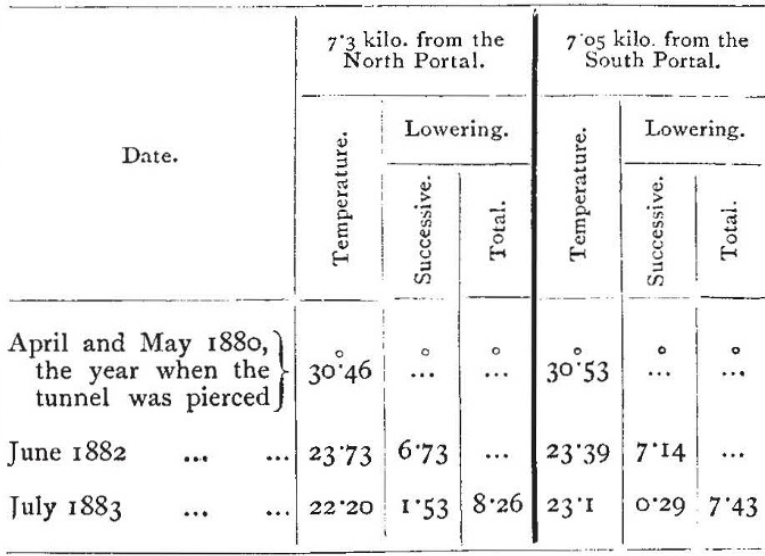

Above are Centigrade.

Although the works were carried on with energy, and with all the best appliances then known, the time occupied was ten years; but the most serious feature of the work was the heavy mortality amongst the men : no less than 600 deaths occurred, including those of both the engineer and contractor.

From the experience then gained, great improvements have been introduced into the works of the Simplon, as will be described later on; but the heavy loss of life in the St. Gothard was due to insufficient ventilation; the high temperature; the exposure of the men to the Alpine climate after emerging from the tunnel; the want of care as to the changing of the men's wet mining clothes; and the poor character of the food with which the men supplied themselves. All this has been greatly ameliorated, and even in English tunnels certain improvements have been introduced, which were brought from Switzerland.

The traffic through the tunnel has so largely increased that the question of ventilation became of pressing importance, and the system of Signor Saccardo, the well-known Government inspector of railways and engineer of Bologna, has been installed, which is an ingenious application of the injector system. One of the first introductions of this method was in the case of the Pracchia Tunnel, on the main line between Florence and Bologna, through the Apennines. This is a railway of single line, and was built many years ago by the late Mr. Brassey. There are 52 tunnels in all, but those on the eastern side are of comparatively little importance. On the western slope the gradient nearly throughout is 25 per thousand (or 1 in 40), and it is here the greatest difficulty exists. There are several tunnels whose lengths approximate to ICOO, 2000 and 3000 yards, and the traffic is both heavy and frequent, the locomotives very powerful, with eight wheels coupled.

Under any conditions of wind the state of the longest tunnel is bad, but when the wind is blowing in at the lower end at the same time that a heavy goods or passenger train is ascending the gradient, a state of affairs is produced which is almost insupportable, and one might as conveniently travel in a furnace flue.

NO. 1603 , VOL. 62] 
A heavy train of dining and sleeping carriages, with two engines, conveying one of the crowned heads of Europe and suite, arrived at the exit of Pracchia Tunnel with both enginemen and both firemen insensible; and in other cases passengers have been seriously affected.

Owing to the height of the mountain no shafts are available; but Signor Saccardo places a ventilating fan near the mouth of the tunnel, and blows air into it through the annular space which exists between the arch of the tunnel and the gauge of maximum construction (Fig. 6). The results are renarkable; the volumes of air thrown into the tunnel per minute being as follows :-

$$
\begin{array}{rrrrrr}
\text { Direct from the fan } & \ldots & \ldots & \ldots & \ldots & \begin{array}{r}
\text { cub. ft. } \\
16 \mathrm{r}, 860
\end{array} \\
\text { Induced draught through open tunnel mouth } & \begin{array}{r}
48,140 \\
\text { Total }
\end{array} \quad \ldots & \ldots & \ldots & 210,000
\end{array}
$$

Or roo cubic metres per second.

The temperature of the tunnel air before the fan was started was $107^{\circ} \mathrm{F}$., with 97 per cent. of moisture, whereas, after the fan had been running a few minutes the temperature was $8 \mathrm{I}^{\circ} \mathrm{F}$. or a lowering of $26^{\circ} \mathrm{F}$., and the tunnel was cool and free from smoke and vapour.
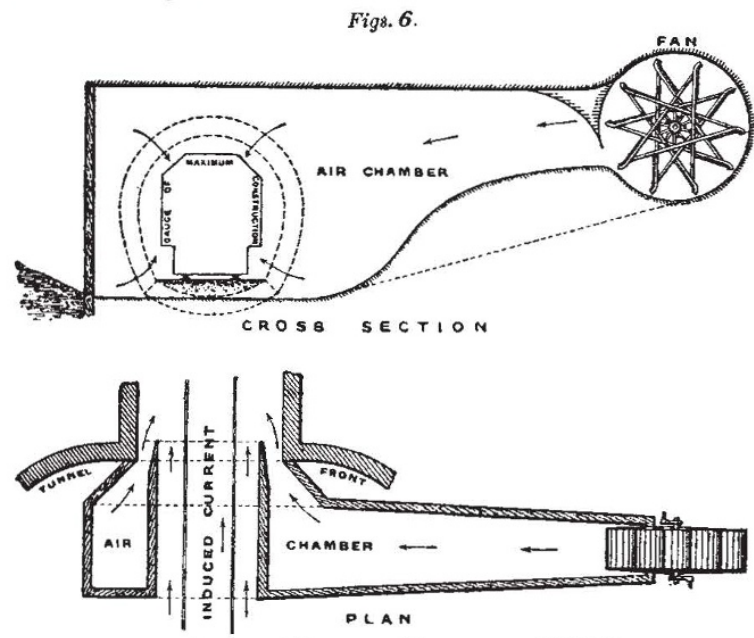

The saccardo Sygtem of Ventilating Tunnels.

One can travel through with both windows open and feel no inconvenience, the only remark of the brakesman riding on the top of the waggons and carriages being that he finds it almost too cold.

This application is without doubt the solution of the difficul problem of tunnel ventilation under high mountains, and elsewhere where shafts are not available, and where electric traction is not applicable.

This system has within the last twelve months been brought into operation on the St. Gothard, with the most satisfactory results. Careful experiments are being made, but there is no doubt that the problem has been solved.

In addition to these tunnels, the Saccardo system has been applied to the Giovi Tunnel near Genoa-3300 metres in length-and is being installed on the Giovi Tunnel on the Genoa-Ronco Railway, 8303 metres in length, besides on some seven other tunnels in Italy; and plans are being prepared for the Mont Cenis.

\section{The Simplon Tunnel.}

This tunnel is now in rapid course of construction, the total length of gallery driven up to the end of April being as follows :- -

$$
\begin{array}{lllll}
\text { On the north or Brigue side of the Alps } & \ldots & \begin{array}{l}
\text { yards } \\
\text { Ond }
\end{array} \\
\text { On the south or Iselle } \ldots & \ldots & \ldots & \ldots & 2350
\end{array}
$$

Or over three miles in little more than eighteen months, in cluding the necessarily slow progress at the commencement.

The total distance between the two portals will be 21,564 yards, or 12.26 miles. A gallery of direction has been driven at both ends until the actual tunnels are reached, so as to form NO. I603, VOL. 62 ] a directly straight line for the accurate alignment of the work from end to end.

This great undertaking will consist of two single-line tunnels running parallel one to the other, at a distance apart from centre to centre of 55 feet 9 inches; and one of the chief features is the much lower altitude of the rails above sea-level than any of the other Alpine tunnels. This altitude is at its highest point 2314 feet, being 1474 feet lower level than that of the St. Gothard, 1934 feet lower than that of the Mont Cenis, and 1986 feet than that of the Ariberg. This is a matter of great importance in the question of haulage of all the traffic.

The tunnel enters the mountain at the present level of the railway at Brigue, so that no costly approaches are requisite on this side.

Admirable arrangements have been made for the welfare of the men, to avoid the heavy death-rate which occurred on the St. Gothard, and it may be interesting to state what some of these are. For every cubic foot of air sent into the latter tunnel, fifty times as much will be delivered into the Simplon. Special arrangements are made for cooling the air by means of fine jets of water and spray.

The men on emerging from their work, wet through and fatigued, are not allowed to go from the warm headings into the cold Alpine air outside, but pass into a large building which is suitably warmed, and where they change their mining clothes and are provided with hot and cold douche baths. They put on warm dry clothes, and can obtain excellent food at a moderate cost before returning to their homes. Their wet and dirty mining clothes are taken charge of by appointed custodians, who dry and clean them ready for the morrow's work. These and other precautions are expected to reduce the death-rate to a very great extent.

With a view to the rapid advancement of the work, the late M. Brandt, whose death is greatly to be deplored, devised after his long experience on the St. Gothard his now well-known drill. As details of this have been published, and as they would he too technical for this evening's discourse, it will only be necessary to refer to them briefly. This drill is non-percussive, nor is it armed with diamond. It is a rotatory drill 3 inches in diameter with a pressure on the cutting points of ro tons moving at slow speed, but capable of being acclerated at pleasure, and of being rapidly withdrawn.

The progress of each of the two faces during the month of April last has averaged $I 7$ feet $3 \frac{1}{\frac{1}{2}}$ inches per day, and is a remarkable corroboration of the speed estimated by the engineers four years ago. The estimate was as follows:-

ist year, the daily progress at each face would be $\ldots \quad 8.85$ feet and ," $, \quad ", \quad, \quad, \quad \ldots 17 \cdot 22$, 3rd ", ", ", $\quad$ ", $\quad, ", \quad \ldots .17 .22$, 4th , $\quad, \quad, \quad,, \quad,, \quad \ldots 2$ I 32,

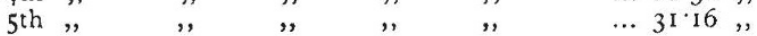

The work is now in its second year, so that the estimated speed is being exceeded. In other words, the tunnel is being driven through granite at a higher speed than is attained in London clay.

It was at one time intended to sink a 20 -inch bore-hole from the village of Berisal to the tunnel, a depth of some 2400 feet, for the purpose of delivering water at high-pressure for the works. This may still be done, but the meandering of the tool might result in the awkward dilemma of having to search for it, in solid rock, below ground.

The probable cost of the work now in hand will be about $2,000,000 \%$., and the time occupied in completing the tunnel ready for traffic is estimated to be $5 \frac{1}{2}$ years, a penalty or a bonus, as the case may be, for delay or acceleration being fixed at $200 l$. a day.

\section{UNIVERSIT Y AND EDUCATIONAL} INTELLIGENCE.

OXFORD. - The following is the text of the speech with which Prof. J. Mark Baldwin, professor of psychology in Princeton University, was presented for the degree of D.Sc. honoris causa. This is the first time the degree has been conferred in Oxford, it having been created only quite recently. The speech was written by Mr. A. C. Clark, of Queen's College, and Prof. Baldwin was presented by Prof. E. B. Elliot, F.R.S., in the absence of Prof. Love, F.R.S., who would in the ordinary 